\title{
BMJ Open Index coronary angiography use in Manitoba, Canada: a population-level descriptive analysis of First Nations and non-First Nations recipients
}

Annette S H Schultz, ${ }^{1}$ Lindsey Dahl, ${ }^{1}$ Elizabeth McGibbon, ${ }^{2} \mathrm{R}$ Jarvis Brownlie, ${ }^{3}$ Catherine Cook, ${ }^{4}$ Basem Elbarouni, ${ }^{5}$ Alan Katz, ${ }^{6}$ Thang Nguyen, ${ }^{5}$ Jo Ann Sawatzky, ${ }^{1}$ Moneca Sinclaire, ${ }^{1}$ Karen Throndson, ${ }^{7}$ Randy Fransoo ${ }^{8}$

To cite: Schultz ASH, Dahl L, McGibbon E, et al. Index coronary angiography use in Manitoba, Canada: a populationlevel descriptive analysis of First Nations and non-First Nations recipients. BMJ Open 2018;8:e020856. doi:10.1136/ bmjopen-2017-020856

- Prepublication history for this paper is available online. To view these files, please visit the journal online (http://dx.doi. org/10.1136/bmjopen-2017020856).

Received 28 November 2017 Revised 8 February 2018 Accepted 22 February 2018

Check for updates

For numbered affiliations see end of article.

Correspondence to Dr Annette S H Schultz; annette_schultz@umanitoba.ca

\section{ABSTRACT}

Objectives To investigate recipient characteristics and rates of index angiography among First Nations (FN) and non-FN populations in Manitoba, Canada.

Setting Population-based, secondary analysis of provincial administrative health data.

Participants All adults 18 years or older who received an index angiogram between 2000/2001 and 2008/2009.

Primary and secondary outcome measures (1) Descriptive statistics for age, sex, income quintile by rural and urban residency and Charlson Comorbidity Index for FN and non-FN recipients. (2) Annual index angiogram rates for $\mathrm{FN}$ and non-FN populations and among those rates of 'urgent' angiograms based on acute myocardial infarction (AMI)-related hospitalisations during the previous 7 days. (3) Proportions of people who did not receive an angiogram in the 20 years preceding an ischaemic heart disease (IHD) diagnosis or a cardiovascular death; stratified by age $(<65$ or $\geq 65$ years old).

Results FN recipients were younger (56.3vs63.8 years; $p<0.0001$ ) and had higher Charlson Comorbidity scores (1.32vs0.78; $p<0.001)$. During all years examined, index angiography rates were lower among FN people (2.67vs3.33 per 1000 population per year; $\mathrm{p}<0.001$ ) with no notable temporal trends. Among the index angiogram recipients, a higher proportion was associated with an AMI-related hospitalisation in the FN group $(28.8 \% v s 25.0 \%$; $p<0.01)$ and in both groups rates significantly increased over time. FN people who died from cardiovascular disease or were older (65+years old) diagnosed with IHD were more likely to have received an angiogram in the preceding 20-30 years $(17.8 \%$ vs $12.5 \% ; p<0.01$ and $50.9 \%$ vs $49.5 \%$; $\mathrm{p}<0.03$, respectively). FN people diagnosed with IHD who were under the age of 65 were less likely to have received an angiogram $(47.8 \%$ vs $53.1 \% ; p<0.01)$ Conclusions Index angiogram use differences are suggested between FN and non-FN populations, which may contribute to reported IHD disparities. Investigating factors driving these rates will determine any association between ethnicity and angiography services.
Strengths and limitations of this study

- Population-based study of all index coronary angiograms performed between 2000/2001 and 2008/2009 within a universal healthcare system.

- Study of differences in coronary angiography between First Nations and non-First Nations populations in Canada are novel.

- Investigation of angiography use trends among First Nations and non-First Nations populations is multifaceted by addressing three objectives.

- Retrospective analysis of administrative data is unable to identify clinical appropriateness of the angiograms performed but can identify differences in rates.

- Crude rates of index angiography reported, which did not adjust for demographic or clinical differences between the two populations.

\section{INTRODUCTION}

Globally, ischaemic heart disease (IHD) remains the single most frequent cause of mortality. ${ }^{1}$ While still responsible for approximately $13 \%$ of deaths in Canada in 2013, rates of IHD deaths have been decreasing. ${ }^{2}$ This trend is due to multiple factors, including reduction of risk factors, advances in evidence-based medical therapies, such as statins and revascularisation procedures, such as percutaneous coronary intervention (PCI) and coronary artery bypass graft (CABG) surgery. ${ }^{3-7}$ Despite these improvements, First Nations (FN) populations in Canada have a higher burden of $\operatorname{IHD}^{89}$ and have not experienced the same rate of reduction in mortality over the last few decades. ${ }^{10}{ }^{11}$ In this article, our goal is to advance an understanding of cardiac health disparities reported among FN peoples in Canada by presenting the first phase of a larger study focused on heart health among FN people living in Manitoba, Canada. 
Conventional risk factors such as obesity, hypertension, atherosclerosis, diabetes, smoking and diet, ${ }^{8-10 ~ 12-14}$ are most often cited as causes of cardiovascular health outcomes among FN populations. These risk factors are often attributed to individuals and their lifestyle choices rather than the persistent effects of colonisation and related impacts on health and health services. ${ }^{15}$ Racial differences have also been demonstrated in rates of important cardiovascular therapies, such as surgery and medications. ${ }^{16}{ }^{17}$ Assessing the state of the coronary arteries through an initial angiogram is an important component of cardiovascular care to inform treatment decisions to manage IHD symptoms. ${ }^{18}$ This procedure reveals the presence and severity of vascular occlusion among coronary arteries, informing the potential need for and feasibility of revascularisation procedures. It can be performed on an elective basis, such as in patients with suspected IHD, or urgently, such as when hospitalised for an acute myocardial infarction (AMI).

Two recent Canadian studies revealed lower rates of angiography following an AMI in FN patients when compared with non-FN counterparts. ${ }^{119}$ However, among patients who received an angiogram, there was no difference between the two groups in the likelihood of undergoing PCI or CABG. ${ }^{19}$ Therefore, the initial decision to perform an angiogram may play a significant role in cardiovascular health disparities between FN and non-FN people who experience an AMI. In the USA, the complex pathways of causation and clinical decision-making in terms of cardiac care have been investigated, and findings consistently indicate racial disparities in access to treatment. ${ }^{20-25}$ Given evidence of racialised differences in receiving an angiogram and knowing that angiograms are performed at times unrelated to an AMI investigating population-level angiogram use may contribute important new evidence about cardiac care access, along with health services influence on cardiovascular disease (CVD) burden.

This study is part of a larger research project that investigates various health and health service use outcomes among index angiogram recipients in Manitoba. In this article, we report the results of a retrospective population-based investigation of all index angiograms among FN and non-FN recipients in Manitoba over a 9-year period (2000/2001 to 2008/2009). The three study objectives were: (1) to describe demographic and comorbidity characteristics of both $\mathrm{FN}$ and non-FN index angiogram recipients; (2) to investigate trends in $\mathrm{FN}$ and non-FN index angiogram use rates over time, including angiograms associated with a recent AMI and (3) to compare the proportions of FN and non-FN Manitobans who did not receive an angiogram, specifically among those with an IHD diagnosis or those who died from CVD. The first two objectives aimed to extend our understanding of angiography use and illustrate differences between the two groups. The third addressed a concern raised by Elders regarding racialised biases within healthcare that may result in some patients not receiving angiography despite being suitable candidates. We designed the third objective based on this concern, as well as the knowledge that previous studies demonstrate racialised referral and treatment preferences. ${ }^{20}$

\section{METHODS}

\section{Canadian and Manitoba context}

In Canada, the term 'Indigenous' commonly represents people who self-report as either First Nations, Métis or Inuit. Of the approximately 36 million people in Canada, $4 \%$ identify as Indigenous and more than half $(61 \%)$ of the Indigenous population are $\mathrm{FN}^{26}$ There were 195900 Indigenous people living in Manitoba in 2011, comprising $17 \%$ of the total provincial population, which is the largest proportion among Canadian provinces. ${ }^{27}$ Approximately 58\% (114 230) of the Manitoba Indigenous population are FN, of which 93\% (105 820) are registered status Indians under the Indian Act.

In Canada, healthcare services are publicly funded, providing universal coverage for all medically necessary hospital, physician and specialist services. Identification of medically necessary services is made at the provincial and territory level, through consultations between government and various health professional colleges. Healthcare services for status FN peoples living on-reserve (primarily public health services and limited primary healthcare) are funded, and in many cases delivered, through federal programmes. ${ }^{28}$ Meanwhile, hospital, physician and specialist services are funded by provincial governments regardless of FN status. ${ }^{28}$ In Manitoba, this includes all cardiac services, and angiogram procedures are available at a tertiary hospital located in the provincial capital city of Winnipeg. Thus, all angiogram procedures provided to FN and non-FN patients in Manitoba are captured in the provincial administrative data system.

\section{Design}

This study analysed health administrative data from the province of Manitoba (population 1.3 million). The Manitoba Population Research Data Repository, housed at the Manitoba Centre for Health Policy (MCHP), contains records of all healthcare services provided through the Manitoba healthcare system, as well as a variety of datasets from other domains (ie, education, social services). Repository data remain linkable at the individual level using a scrambled identifier to ensure privacy. The specific data files used in this study included:

1. The Manitoba Health Insurance Registry, which includes person-level demographic information and residential postal codes for virtually all Manitobans (FN and other);

2. Hospital Discharge Abstracts, which contain information on all hospitalisations in Manitoba, including diagnoses and procedures provided (ie, International Classification of Diseases 10th Revision, Canada (ICD10-CA) codes); 
3. Medical Services, which contains information on ambulatory physician visits in Manitoba and the associated ICD code for each visit;

4. The Vital Statistics Mortality Registry, which includes everyone who has died in Manitoba and the primary cause of death, as well as other underlying causes or external causes of death;

5. The Indian Registry System (IRS), which is a national database maintained by Indian and Northern Affairs Canada (INAC) and contains information on all registered treaty FN people to determine eligibility for benefits under the Non-Insured Health Benefits Program. Since ethnic information is not available in Manitoba hospital abstracts, identification of FN patients within administrative data requires linkage of the INAC Indian Status Registry with the Personal Health Information Number held by Manitoba Health;

6. The Drug Program Information Network, which contains information on all prescription drugs dispensed from community-based pharmacies in Manitoba.

As part of a larger research project, this study is supported by an interdisciplinary research team and collaborations with FN Elders. Study approval was obtained from the University of Manitoba's Education and Nursing Research Ethics Board, the Manitoba Health Information Privacy Committee and the Health Information Research Governance Committee at Nanaandawewigamig, the First Nations Health and Social Secretariat of Manitoba (FNHSSM). The linkage of the IRS data file and Health Registry was approved through the research protocols of Assembly of Manitoba Chiefs prior to 2014 and Nanaandawewigamig FNHSSM thereafter.

\section{Study population and cohort definitions}

The first two objectives included all adult Manitobans (18+ years) who received an index angiogram between 2000/2001 and 2008/2009. Angiograms were identified from the Hospital Discharge Abstracts data file using specific Canadian Classification of Health Interventions procedure codes (table 1) and were considered 'index' if the patient had not previously received an angiogram or invasive cardiac procedure in the preceding 365 days. Index angiograms indicate entry into cardiac care services through initial assessment of coronary anatomy and are used to inform treatment decisions.

Health services administrative data are ideal for investigating index angiogram recipients; however, data use can be challenging when the aim is to investigate patients who did not receive an angiogram but who may have benefited from receiving one. To address the third study objective, and the issue raised by Elders, two cohorts were formed in an attempt to identify individuals who have not received an index angiogram but in the health administrative data appeared to have cardiac health conditions. The first cohort included all adult Manitobans identified as having IHD between 2010/2011 and 2014/2015. IHD cases were identified with a validated algorithm that included patients who had: (1) one or
Table 1 ICD and CCI procedural code definitions

\begin{tabular}{|c|c|c|}
\hline $\begin{array}{l}\text { Procedure/ } \\
\text { Condition }\end{array}$ & Codes & Definition \\
\hline \multirow[t]{2}{*}{ Angiography } & $\mathrm{CCl}$ & \\
\hline & 3.IP.10 & Coronary angiography \\
\hline \multirow[t]{12}{*}{ IHD } & ICD-9-CM 410 & \\
\hline & 410 & $\begin{array}{l}\text { Acute myocardial } \\
\text { infarction }\end{array}$ \\
\hline & 411 & $\begin{array}{l}\text { Other acute and sub } \\
\text { acute forms of ischaemic } \\
\text { heart disease }\end{array}$ \\
\hline & 412 & Old myocardial infarction \\
\hline & 413 & Angina pectoris \\
\hline & 414 & $\begin{array}{l}\text { Other forms of chronic } \\
\text { ischaemic heart disease }\end{array}$ \\
\hline & ICD-10-CA & \\
\hline & 120 & Angina pectoris \\
\hline & 121 & $\begin{array}{l}\text { ST elevation and non- } \\
\text { ST elevation myocardial } \\
\text { infarction }\end{array}$ \\
\hline & 122 & $\begin{array}{l}\text { Subsequent ST elevation } \\
\text { and non-ST elevation } \\
\text { myocardial infarction }\end{array}$ \\
\hline & 124 & $\begin{array}{l}\text { Other acute ischaemic } \\
\text { heart diseases }\end{array}$ \\
\hline & 125 & $\begin{array}{l}\text { Chronic ischaemic heart } \\
\text { disease }\end{array}$ \\
\hline \multirow[t]{4}{*}{ AMI } & ICD-9-CM & \\
\hline & 410 & $\begin{array}{l}\text { Acute myocardial } \\
\text { infarction }\end{array}$ \\
\hline & ICD-10-CA & \\
\hline & 121 & $\begin{array}{l}\text { ST elevation and non } \\
\text { ST elevation myocardial } \\
\text { infarction }\end{array}$ \\
\hline
\end{tabular}

$\mathrm{CCl}$, Canadian Classification of Health Interventions; ICD-9-CM, International Classification of Diseases Ninth Revision, Clinical Modification; ICD-10-CA, ICD 10th Revision, Canada; IHD, ischaemic heart disease.

more hospitalisations or had two or more physician visits that resulted in specific ICD-9 Clinical Modification (CM) or ICD-10-CA diagnostic codes (table 1) or (2) one physician visit with these codes and two or more prescriptions dispensed for medications to treat IHD symptoms. ${ }^{29}$ The second cohort included all adult Manitobans who were coded in vital statistics as having died between 1984 and 2015 with a primary cause of death in the cardiovascular chapter of the ICD-10-CA diagnostic system.

\section{Statistical analysis}

All analyses related to the three study objectives were done on the secure server at MCHP, using SAS statistical analysis software, V.9.4 (SAS Institute). Statistical significance for all tests was set at $\mathrm{p}<0.05$. 


\section{Angiogram recipient characteristics}

Descriptive characteristics of $\mathrm{FN}$ and non-FN people who received an index angiogram between 2000/2001 and 2008/2009 were measured at the time of the angiogram and included: age, sex, area of residence, area-level income group (quintiles) and Charlson Comorbidity Index scores. Urban residency included those residing in Winnipeg, the only urban Manitoba setting where angiogram services are available. Rural residency included all other Manitoba areas. Income quintiles were calculated for urban and rural residence separately, using postal codes and 2006 Canadian census average household incomes, which has been used in previous research as a predictor of health and health service use. ${ }^{30-32}$ The Charlson Comorbidity Index provided a valid measure of each patient's comorbidity status and was calculated based on ICD codes from the hospital discharge abstract and physician claims databases. ${ }^{33}$ The frequencies for each condition listed in the Charlson Comorbidity Index are presented, but statistical tests for differences between groups were not conducted for this study. Differences for all other characteristics between $\mathrm{FN}$ and non-FN recipients were tested for significance using t-tests and $\chi^{2}$ tests.

\section{Index angiography trends}

Annual crude rates of index angiograms were calculated among FN and non-FN populations for each year from $2000 / 2001$ to $2008 / 2009$ along with an overall average of annual rates. Annual FN and non-FN population counts of adults 18 years of age or older as of December 31 were obtained and used as the denominators for each rate calculation. Angiograms performed within 7 days of the patient being hospitalised for an AMI were identified and categorised as urgent. An AMI was defined using the following validated definition: a hospitalisation with a specific ICD-9-CM or ICD-10-CA code (table 1) listed as the most responsible diagnosis and a length of stay of three or more days (unless the patient died in hospital, in which case length of stay was not relevant). ${ }^{34}$ All differences in annual angiography rates and proportions of urgent angiograms between $\mathrm{FN}$ and non-FN populations were tested for significance using $\chi^{2}$ tests. Trends over time were analysed with linear regression models fit to the annual rates, and 95\% CI were calculated around the regression slopes.

\section{Angiography among IHD and CVD death cohorts}

The IHD cohort was stratified by FN status and age $(<65,65+$ years as of 31 December 2012) and examined to determine if an angiogram was performed anytime between 1984/1985 and 2014/2015. The cohort of individuals who died from CVD were also stratified by $\mathrm{FN}$ status and age $(<65,65+y e a r s$ at the time of index angiogram) and examined for receipt of an angiogram in the 20 years prior to death. Proportions of FN and non-FN people in both cohorts who did not receive an angiogram were compared and tested for differences using $\chi^{2}$ tests.

\section{RESULTS}

\section{Recipient characteristics}

In total, 25816 adult Manitobans received an index angiogram between 2000/2001 and 2008/2009, of which 1499 $(5.8 \%)$ were $\mathrm{FN}$ (table 2$). \mathrm{FN}$ recipients were younger ( 56.2 vs 63.8 years; $\mathrm{p}<0.0001)$, less likely to be male $(58.7 \%$ vs $65.8 \% ; \mathrm{p}<0.0001)$, more likely to reside in rural areas (75.8\% vs 36.4\%; p<0.0001) and had higher Charlson Comorbidity Index scores (1.3 vs 0.78; p<0.0001). Among rural and urban $\mathrm{FN}$ recipients, the proportions were highest for those living in the lowest income areas and decreased in each subsequent income quintile. Among the non-FN group, the proportions of index angiograms were more evenly distributed across the five income levels regardless of residence.

\section{Trends in angiogram and urgent angiogram rates}

The overall average angiogram rate between 2000/2001 and 2008/2009 was significantly lower in the FN population (2.67 vs 3.33 per 1000 population per year; $\mathrm{p}<0.0001$; table 3). Annual angiogram rates were lower in the $\mathrm{FN}$ population each year and statistically different in 5 of the 9 years analysed. Figure 1 shows no significant temporal trends in angiogram rates in either group.

Of all index angiograms performed between 2000/2001 and 2008/2009, a higher proportion were related to a hospitalisation for AMI (ie, categorised as urgent) among FN recipients compared with non-FN recipients $(28.8 \%$ vs $25.0 \%$; $=0.006$; table 4 ). Higher proportions among FN recipients were observed for most years studied, although only the rates in $2003 / 2004$ were significantly different $(33.9 \%$ vs $22.5 \% ; \mathrm{p}=0.03)$. figure 2 shows the proportion of urgent angiograms significantly increased from 2000/2001 to 2008/2009 among both FN recipients (slope $=1.82 \%$ per year; $95 \%$ CI $0.73 \%$ to $2.91 \%$ ) and non-FN recipients (slope $=2.16 \%$ per year; $95 \%$ CI $1.63 \%$ to $2.69 \%$ ). Although the increase occurred steadily over time among non-FN population, the pattern among FN population was more variable.

\section{Angiography among IHD and CVD-related death cohorts}

The proportion of adult Manitobans with an IHD diagnosis between 2010/2011 and 2014/2015 who had not received an angiogram anytime since 1984/1985 were not significantly different between $\mathrm{FN}$ and non-FN groups (table 5). However, significant differences were observed with age stratification, where higher proportion of FN patients in the younger age group (52.2\% vs $46.9 \%, \mathrm{p}<0.01)$ and a lower proportion in the older age group (49.1\% vs $51.8 \%, \mathrm{p}<0.003)$ had not received an angiogram.

Among Manitobans who died from CVD, a significantly lower proportion of FN people had not received an angiogram within the 20 years before death compared with non-FN people $(82.2 \%$ vs $87.5 \%, \mathrm{p}<0.01$; table 6$)$. This difference persisted when the groups were stratified by age ( $<65$ years, $80.3 \%$ vs $83.6 \%, \mathrm{p}<0.01 ; \geq 65$ years, $83.7 \%$ vs $88.1 \%, \mathrm{p}<0.01)$. 
Table 2 Characteristics of index angiogram patients by First Nations status (2000/2001-2008/2009)

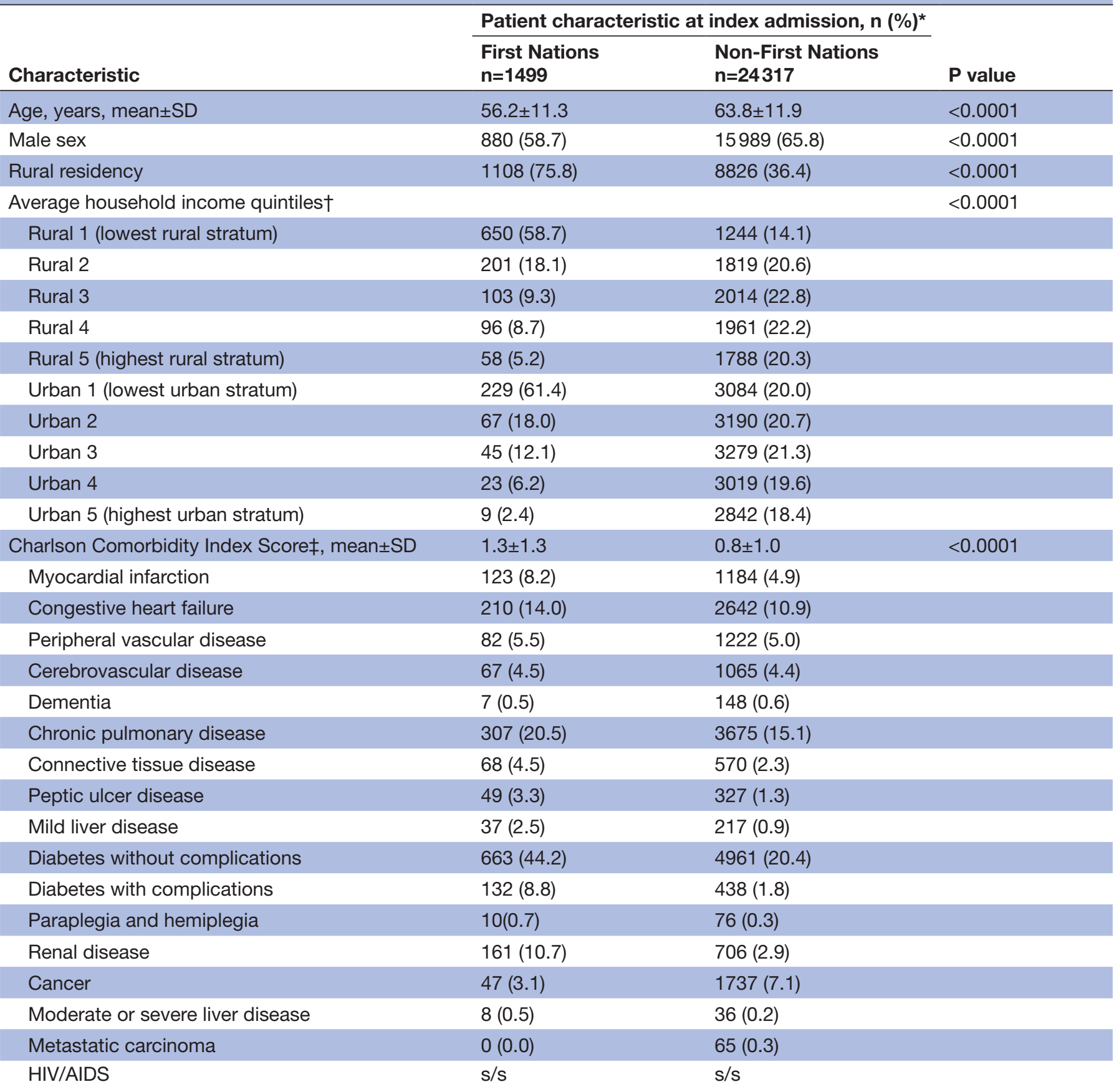

Total counts from the rural and urban income quintiles do not equal the total count of angiograms because some incomes could not be found. *Unless otherwise indicated.

†Percentages are calculated for rural and urban areas separately.

¥Statistical comparisons were not conducted on each condition used in the Charlson Comorbidity Index Score calculation.

$\mathrm{s}$, suppressed due to small cell size $(\mathrm{n} \leq 5)$.

\section{DISCUSSION}

Study findings describe FN and non-FN index angiogram recipient sociodemographic and comorbidity characteristics and reveal between group differences. Lower rates of index angiograms among the FN population were demonstrated, but no temporal trends were observed over time in either group. Among Manitobans who received an index angiogram within 7 days of being hospitalised for an AMI, there was a higher proportion in the FN group compared with the non-FN group, and the proportions of these urgent angiograms significantly increased over time in both groups. Approximately 50\% of Manitobans with an IHD diagnosis in 2010/2011 to 2014/2015 had not received an angiogram anytime in the preceding 25-30 years, and there was no significant difference between FN and non-FN groups. Lastly, among 
Table 3 Crude rates of index angiograms per 1000 population by FN status (2000/2001-2008/2009)

\begin{tabular}{|c|c|c|c|c|c|}
\hline \multirow[b]{2}{*}{ Year } & \multicolumn{2}{|l|}{ FN } & \multicolumn{2}{|c|}{ Non-FN } & \multirow[b]{2}{*}{$P$ value } \\
\hline & No. & Rate & No. & Rate & \\
\hline $2000 / 2001$ & 145 & 2.61 & 2735 & 3.40 & 0.0019 \\
\hline 2001/2002 & 171 & 2.98 & 2635 & 3.26 & 0.2578 \\
\hline $2002 / 2003$ & 139 & 2.35 & 2666 & 3.28 & 0.0001 \\
\hline $2003 / 2004$ & 168 & 2.77 & 2759 & 3.37 & 0.0133 \\
\hline $2004 / 2005$ & 142 & 2.28 & 1620 & 3.18 & 0.0001 \\
\hline $2005 / 2006$ & 198 & 3.10 & 1706 & 3.27 & 0.4666 \\
\hline $2006 / 2007$ & 179 & 2.73 & 2562 & 3.08 & 0.1207 \\
\hline $2007 / 2008$ & 152 & 2.26 & 2767 & 3.28 & $<0.0001$ \\
\hline $2008 / 2009$ & 205 & 2.96 & 2867 & 3.37 & 0.0778 \\
\hline Overall & 1499 & 2.67 & 24317 & 3.28 & $<0.0001$ \\
\hline
\end{tabular}

FN, First Nations.

Manitobans who died of a CVD, a higher proportion of non-FN people had not received an angiogram in the preceding 20 years. By addressing angiography use from a population level, this study is a first step in approaching CVD disparities among FN people that moves beyond focusing on a specific cardiovascular disease group and/ or on individual choices and lifestyle factors.

At the time of index angiography, $\mathrm{FN}$ recipients were younger by an average of 7.6 years, less likely to be male, had higher Charlson Comorbidity Index scores and were more likely to reside in rural and lower income areas compared with non-FN recipients. These population rate differences in recipient characteristics are similar to those
Table 4 Proportion of urgent index angiograms by FN status (2000/2001-2008/2009)

\begin{tabular}{|c|c|c|c|c|c|}
\hline \multirow[b]{2}{*}{ Year } & \multicolumn{2}{|l|}{ FN } & \multicolumn{2}{|c|}{ Non-FN } & \multirow[b]{2}{*}{$P$ value } \\
\hline & No. & Per cent & No. & Per cent & \\
\hline $2000 / 2001$ & 30 & 20.7 & 463 & 16.9 & 0.2869 \\
\hline $2001 / 2002$ & 32 & 18.7 & 481 & 18.3 & 0.8918 \\
\hline $2002 / 2003$ & 34 & 24.5 & 591 & 22.2 & 0.5769 \\
\hline $2003 / 2004$ & 57 & 33.9 & 621 & 22.5 & 0.0030 \\
\hline $2004 / 2005$ & 43 & 30.3 & 616 & 23.5 & 0.1086 \\
\hline $2005 / 2006$ & 55 & 27.8 & 647 & 23.9 & 0.2857 \\
\hline $2006 / 2007$ & 59 & 33.0 & 737 & 28.8 & 0.3144 \\
\hline $2007 / 2008$ & 53 & 34.9 & 933 & 33.7 & 0.8123 \\
\hline $2008 / 2009$ & 68 & 33.2 & 977 & 34.1 & 0.8297 \\
\hline Overall & 431 & 28.8 & 6066 & 25.0 & 0.0061 \\
\hline
\end{tabular}

FN, First Nations.

reported among other Indigenous and non-Indigenous populations at the time of cardiovascular-related hospitalisations. ${ }^{1922}{ }^{35-38}$ While it is concerning that FN recipients were younger and had worse health at the time of their index angiogram, at least they had entered the cardiovascular healthcare system.

Although the annual rates of index angiograms varied slightly for both groups, the FN population consistently demonstrated lower rates than the non-FN population. The trend analysis revealed angiography use in both populations remained unchanged during the study period, with the exception of increased rates among those who had an AMI within the 7 days prior to their angiogram.

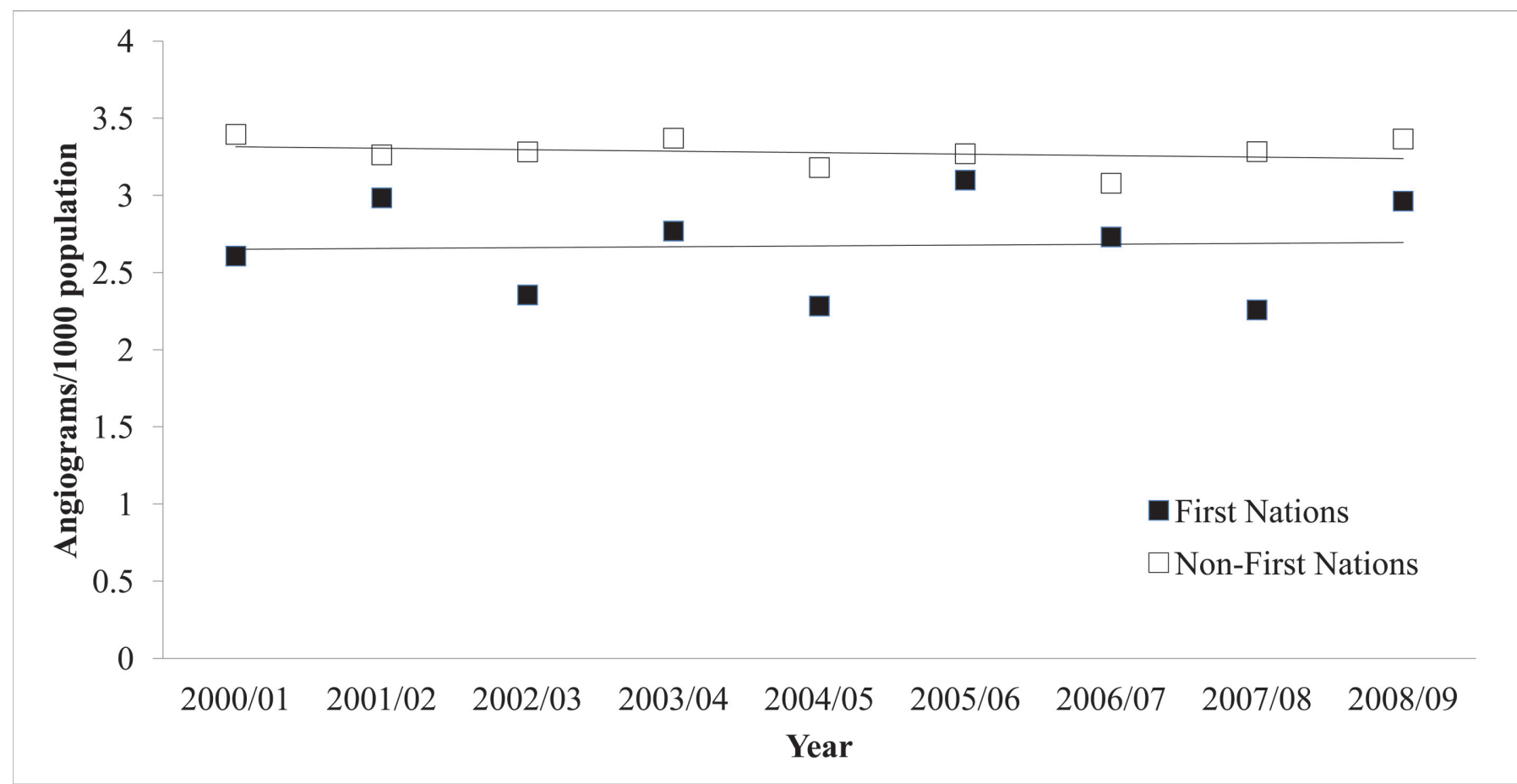

Figure 1 Trends in population-based annual rates of index coronary angiography between 2008/2009 and 2008/2009 by First Nations status. 


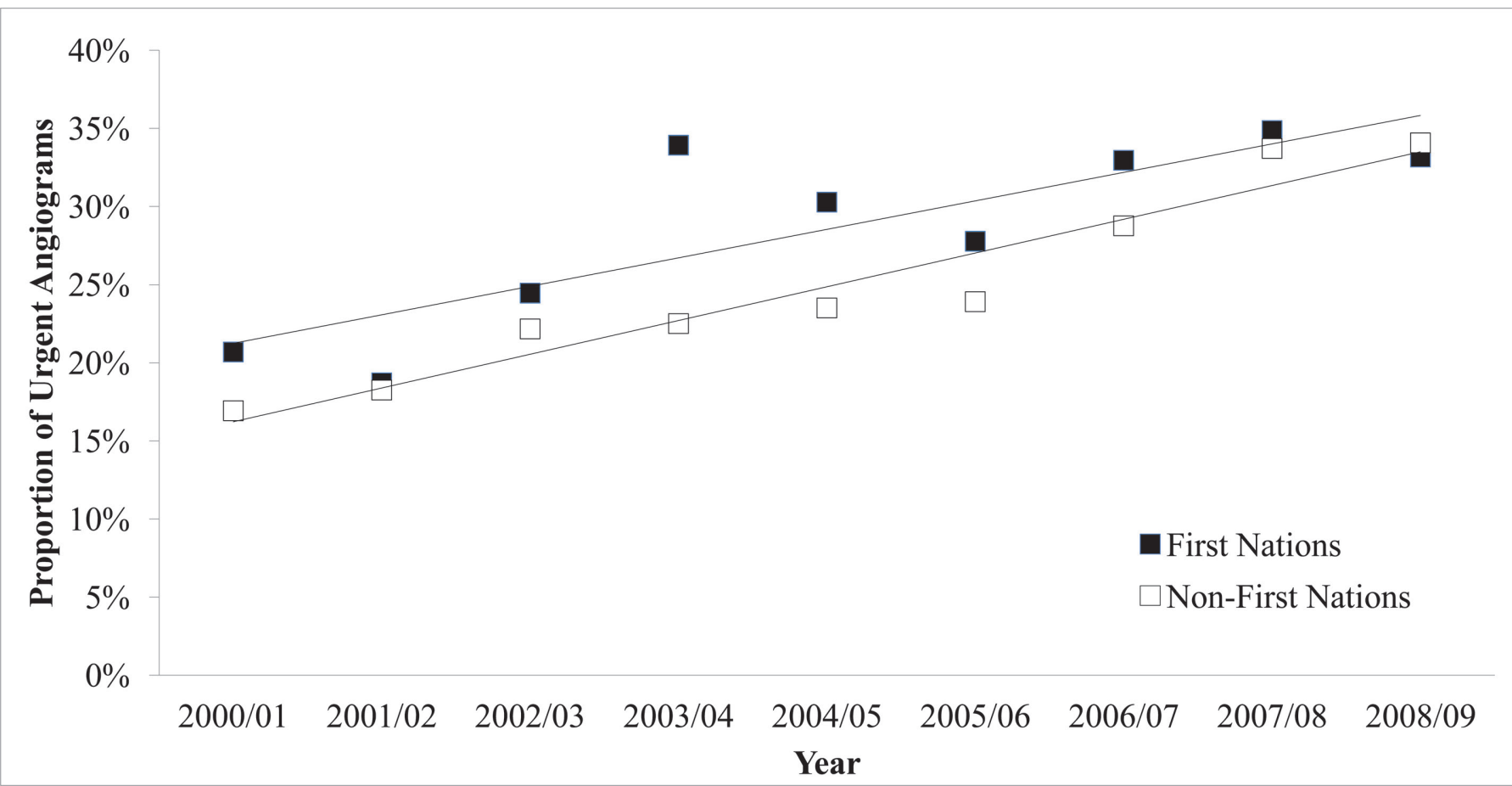

Figure 2 Trends in the proportions of angiograms categorised as urgent (related to an AMI hospitalisation) between 2000/2001 and $2008 / 2009$ by First Nations status.

The proportion of these urgent index angiograms among the FN group was consistently higher than that of the non-FN group, though the difference between the two groups decreased over time. The increasing proportion of urgent angiograms in both groups suggests a practice change away from performing elective angiograms.

While study objectives did not include investigation of factors to explain differences in rates of angiography between FN and non-FN groups, we speculate on two plausible explanations: (1) a lower proportion of $\mathrm{FN}$ people who visited a physician for CVD-related symptoms were referred for angiography and/or (2) a lower proportion of FN people experiencing CVD symptoms visited physicians. For the first explanation, there are many clinical and non-clinical factors that influence clinical decisions regarding angiography. First, older age ( $>65$ years of age) has been associated with a lower likelihood of angiography, ${ }^{39}$ which can be related to higher level of comorbidities that preclude angiography or revascularisation procedures. Guidelines indicate pre-existing conditions such as renal insufficiency and diabetes may increase the risk of subsequent complications. ${ }^{17}$ The FN population in Manitoba is younger than the general population but have a higher level of comorbidity, especially diabetes. ${ }^{40} 41$ Therefore, pre-existing conditions among FN patients may result in a lower proportion for which angiography is deemed appropriate. Alternately, geographical residence may affect rates of angiograms, as the only facilities preforming angiograms were in Winnipeg, and a higher proportion of the FN population live in rural Manitoba areas. However, previous studies suggest age and sex-adjusted rates of cardiac surgeries are higher for Indigenous people (compared with non-Indigenous) in northern rural areas and lower among those living in urban areas. ${ }^{16}$ Given that angiography and cardiac surgery are intertwined, the lower overall rates of angiography for $\mathrm{FN}$ compared with non-FN residents is unlikely explained by living further from the catheterisation facilities. Finally, physician-patient relationships, related societal biases, along with patient preferences and health beliefs all

Table 5 Proportion of individuals with IHD between 2010/2011-2014/2015 who did not receive an angiogram anytime since $1984 / 1985$

\begin{tabular}{|c|c|c|c|c|c|}
\hline & FN & & Non-FN & & \\
\hline Age, year & $\begin{array}{l}\text { No. of patients with } \\
\text { IHD }\end{array}$ & No angiogram (\%) & $\begin{array}{l}\text { No. of patients with } \\
\text { IHD }\end{array}$ & No angiogram (\%) & $P$ value \\
\hline$\geq 65$ & 2069 & $1015(49.1)$ & 55093 & 28559 (51.8) & $<0.03$ \\
\hline Total & 4827 & 2455 (50.9) & 75434 & 38095 (50.5) & $>0.10$ \\
\hline
\end{tabular}

FN, Flrst Nations; IHD, ischaemic heart disease. 
Table 6 Proportion of cardiovascular-related deaths between 1984/1985 and 2014/2015 where the patient did not received an angiogram anytime within 20 years of death

\begin{tabular}{|c|c|c|c|c|c|}
\hline \multirow[b]{2}{*}{ Age, year } & \multicolumn{2}{|l|}{ FN } & \multicolumn{2}{|l|}{ Non-FN } & \multirow[b]{2}{*}{$P$ value } \\
\hline & No. of CV deaths & No angiogram (\%) & No. of CV deaths & No angiogram (\%) & \\
\hline$<65$ & 1384 & 1111 (80.3) & 12682 & 10609 (83.6) & $<0.01$ \\
\hline Total & 3214 & 2643 (82.2) & 102501 & 89697 (87.5) & $<0.01$ \\
\hline
\end{tabular}

CV, cardiovascular; FN, First Nations.

likely influence whether a patient undergoes angiography. ${ }^{20} 23-2542-44$

The second possible explanation suggests that the lower rates of angiography among the FN population may be due to a lower proportion of FN people with cardiac symptoms visit physicians for these symptoms. For various reasons, many FN people view the healthcare system as racist and untrustworthy, with poor communication and care continuity, which influences how they access and use health services. ${ }^{45-47}$ Such system-level barriers to access may result in $\mathrm{FN}$ people postponing cardiac care until an acute event has occurred. This may also be further exacerbated by higher rate of socioeconomic disadvantage experienced among FN populations, as evidence suggests individuals living with SES disadvantage and have IHD symptoms are more likely to prolong seeking healthcare until an AMI. ${ }^{48}$

Underpinning these speculative explanations for angiogram rate differences is the historical and persistent impact of colonisation and structural racism embedded in postcolonial institutions such as healthcare. ${ }^{15}$ 49-54 Moreover, a substantive base of evidence exists regarding experiences of systemic racism being clearly linked to compromised cardiac outcomes $^{1552}$; racism has significant negative and measureable impacts on human biophysiological processes and outcomes. ${ }^{55}$ Furthermore, many social disparities related to income, education, employment and housing exist between $\mathrm{FN}$ and non-FN people, which are all rooted in colonial policies and practices. ${ }^{51}$ Given the inextricable link between health and social indicators, it has been suggested that a nationwide, holistic FN health strategy that addresses the social conditions of $\mathrm{FN}$ people is necessary to improve health and healthcare access for the FN population. ${ }^{53}$

Finally, the third study objective investigated when angiograms were not performed on individuals with cardiac conditions. During the study time period, among proportion of Manitobans who died of a cardiovascular disease or who had an IHD diagnosis but had not received an angiogram did not confirm the concern raised an Elder. FN people, who died of a cardiovascular death, were actually more likely to have received an angiogram in comparison to non-FN Manitobans. While unanticipated, it is possible there were individuals who died of a cardiovascular disease but their death certificate indicated another cause. Regarding Manitoban's with an IHD diagnosis, FN people under the age of 65 were less likely to receive an angiogram in the previous 25-30 years. This finding raises concerns because more than half of the total FN patients in the IHD cohort were less than 65 years. However, it is important to note that these proportions represent the prevalence of IHD during $2010 / 2011$ to $2014 / 2015$ but are unable to reveal the length of time since IHD diagnosis. Furthermore, it is not known whether there are differences in the amount of non-invasive testing for IHD between the groups. If IHD diagnosis was through that form of testing and a path of medical therapy was chosen, then angiogram might not have been necessary.

Several study limitations are notable. First, only FN people registered under the Indian Act were included in the FN group, which means unregistered FN people were included in the non-FN group. However, 93\% of self-reported Manitoba FN people are registered, ${ }^{26}$ therefore, the misclassification bias was small. Second, the non-FN group included other Indigenous people (ie, Métis and Inuit) who also experience a greater burden of CVD. ${ }^{56}$ If their angiography rates are similar to the $\mathrm{FN}$ group, their inclusion in the non-FN group would lead to an underestimation of the rate difference between $\mathrm{FN}$ and non-FN populations. Third, administrative data do not contain information that would allow for an analysis of the appropriateness of angiography. Therefore, it is not known whether angiography was employed more appropriately for one group or the other. The lower rates of angiography in the FN population may be a result of an overuse of the procedure in the non-FN group, which has been reported among African-American and white patients in the USA. ${ }^{57}$ Lastly, the proportion of FN people in Manitoba's total population is highest among all Canadian provinces, which may affect generalisability of study findings. However, overall health status resulting from deteriorating social conditions and the transition from traditional to modern lifestyles has been experienced similarly by FN populations across Canada and is likely that this also applies specifically to cardiovascular heath. ${ }^{1058}$

An additional cautionary note, the analysis of crude and unadjusted rates for underlying differences between the populations influences the interpretation of findings. This is to say that although the rates were lower in the FN population, it is not known whether this is due to their ethnicity or some other factor, such as age or the remoteness of the area they live. Still the results from this study provide important background and context for a future study examining the outcomes of all index angiogram recipients in Manitoba. 


\section{CONCLUSION}

Lower crude angiography rates among Manitoba's FN people compared with the non-FN population were observed, which raises concerns given the higher burden of IHD experienced by the FN population. A variety of factors may be contributing to the lower rates and further research is needed to determine if $\mathrm{FN}$ status is associated with index coronary angiogram access. Whether or not a difference truly exists in the rates of index angiograms, the level of angiogram use among both populations in general has gone unchanged, with the exception of elective versus urgent timing of the angiogram. Findings from this study and future studies may inform health programme and planning, as well as strategies and policies aimed at reducing racial disparities in cardiovascular health and healthcare services.

\section{Author affiliations}

${ }^{1}$ College of Nursing, Rady Faculty of Health Sciences (RFHS), University of Manitoba, Winnipeg, Manitoba, Canada

${ }^{2}$ Rankin School of Nursing Faculty of Health Sciences, St Francis Xavier University, Antigonish, Nova Scotia, Canada

${ }^{3}$ Department of History, Faculty of Arts, University of Manitoba, Winnipeg, Manitoba, Canada

${ }^{4}$ Indigenous Health, Rady Faculty of Health Sciences (RFHS), First Nations, Métis and Inuit Health, Max Rady College of Medicine, University of Manitoba, Winnipeg, Manitoba, Canada

${ }^{5}$ Max Rady College of Medicine, Rady Faculty of Health Sciences (RFHS), University of Manitoba, Winnipeg, Manitoba, Canada

${ }^{6}$ College of Medicine, Rady Faculty of Health Sciences (RFHS), University of Manitoba, Winnipeg, Manitoba, Canada

${ }^{7}$ Clinical Nurse Specialist Cardiac Sciences Program, St Boniface General Hospital, Winnipeg, Manitoba, Canada

${ }^{8}$ Manitoba Centre for Health Policy, Rady Faculty of Health Sciences (RFHS), University of Manitoba, Winnipeg, Manitoba, Canada

Acknowledgements We acknowledge the Manitoba Centre for Health Policy for use of data contained in the Manitoba Population Research Data Repository under HIPC File No. 2014/2015-34. The results and conclusions are those of the authors and no official endorsement by the Manitoba Centre for Health Policy, Manitoba Health Seniors and Active Living or other data providers is intended or should be inferred. We acknowledge and thank Nanaandawewigamig Research team for their review and comments on this article and acknowledge that MFNs HIRGC has approved this project in development and final stages in 2015. We also gratefully acknowledge Rady Faculty of Health Sciences Elder Mary Wilson, Grandmother of the Four Directions for her insights concerning this manuscript and her involvement in the larger study.

Contributors The lead author (ASHS) and second author (LD) cocreated the initial manuscript draft; and we have been responsible for integrating critical feedback from all the coauthors (EM, RJB, CC, BE, AK, TN, JAS, MS, KT and RF) All coauthors are coinvestigators on the larger study and with this manuscript have had involvement from conceptualisation of the three objectives to interpretation of findings. Each coauthor has reviewed this manuscript and has provided feedback at least once on previous drafts. In addition, the third author (EM) has been a significant contributor regarding systemic issues and racism within healthcare, and the final author (RF) oversaw all statistical analysis on this study.

Funding CIHR: MOP-136904; funded through the Aboriginal People's Health Institute.

Competing interests None declared.

Patient consent Detail has been removed from this case description/these case descriptions to ensure anonymity. The editors and reviewers have seen the detailed information available and are satisfied that the information backs up the case the authors are making.
Ethics approval University of Manitoba, Education and Nursing Ethics Review Board; Manitoba Health Information Privacy Committee; Nanaandawewigamig First Nations Health and Social Secretariat of Manitoba.

Provenance and peer review Not commissioned; externally peer reviewed.

Data sharing statement No additional data are available.

Open Access This is an Open Access article distributed in accordance with the Creative Commons Attribution Non Commercial (CC BY-NC 4.0) license, which permits others to distribute, remix, adapt, build upon this work non-commercially, and license their derivative works on different terms, provided the original work is properly cited and the use is non-commercial. See: http://creativecommons.org/ licenses/by-nc/4.0/

(C) Article author(s) (or their employer(s) unless otherwise stated in the text of the article) 2018. All rights reserved. No commercial use is permitted unless otherwise expressly granted.

\section{REFERENCES}

1. World Health Organization. The top 10 causes of death (Fact sheet No. 310). 2017 http://www.who.int/mediacentre/factsheets/fs310/ en/.htm (accessed 5 Jul 2017).

2. Statistics Canada. Table 102-0529 - Deaths, by cause, Chapter IX: Diseases of the circulatory system (100 to 199), age group and sex, Canada, annual (number), CANSIM (database). (accessed 5 Jul 2017)

3. Taylor F, Ward K, Moore TH, et al. Statins for the primary prevention of cardiovascular disease. Cochrane Database Syst Rev 2011:CD004816.

4. Critchley JA, Capewell S. Mortality risk reduction associated with smoking cessation in patients with coronary heart disease: a systematic review. JAMA 2003;290:86-97.

5. Tu JV, Nardi L, Fang J, et al. Canadian Cardiovascular Outcomes Research Team. National trends in rates of death and hospital admissions related to acute myocardial infarction, heart failure and stroke, 1994-2004. CMAJ 2009;180:E118-25.

6. Ford ES, Ajani UA, Croft JB, et al. Explaining the decrease in U.S. deaths from coronary disease, 1980-2000. N Engl J Med 2007;356:2388-98.

7. Wijeysundera HC, Machado M, Farahati F, et al. Association of temporal trends in risk factors and treatment uptake with coronary heart disease mortality, 1994-2005. JAMA 2010;303:1841-7.

8. Anand SS, Yusuf S, Jacobs R, et al. Risk factors, atherosclerosis, and cardiovascular disease among Aboriginal people in Canada: the Study of Health Assessment and Risk Evaluation in Aboriginal Peoples (SHARE-AP). The Lancet 2001;358:1147-53.

9. Shah BR, Hux JE, Zinman B. Increasing rates of ischemic heart disease in the native population of Ontario, Canada. Arch Intern Med 2000:160:1862-6.

10. Young TK. Cardiovascular health among Canada's aboriginal populations: a review. Heart Lung Circ 2012;21:618-22.

11. Information $\mathrm{ClHI}$. Hospital care for heart attacks among first nation, inuit and metis. Canada: $\mathrm{ClHI}, 2013$.

12. Katzmarzyk PT. Obesity and physical activity among Aboriginal Canadians. Obesity 2008:16:184-90.

13. Tjepkema M, Wilkins R, Goedhuis N, et al. Cardiovascular disease mortality among First Nations people in Canada, 1991-2001. Chronic Dis Inj Can 2012;32:200-7.

14. Lix LM, Bruce S, Sarkar J, et al. Risk factors and chronic conditions among Aboriginal and non-Aboriginal populations. Health Rep 2009;20:21

15. McGibbon E, Waldron I, Jackson J. The social determinants of cardiovascular disease: time for a focus on racism. Diversity \& Equality in Health \& Care 2013.

16. Sood MM, Tangri N, Komenda P, et al. Cardiovascular Health Research in Manitoba (CHaRM) Investigator Group. Incidence, secular trends, and outcomes of cardiac surgery in Aboriginal peoples. Can J Cardiol 2013;29:1629-36.

17. Mehta JL, Bursac Z, Mehta P, et al. Racial disparities in prescriptions for cardioprotective drugs and cardiac outcomes in Veterans Affairs Hospitals. Am J Cardiol 2010;105:1019-23.

18. Scanlon PJ, Faxon DP, Audet AM, et al. ACC/AHA guidelines for coronary angiography. A report of the American College of Cardiology/American Heart Association Task Force on practice guidelines (Committee on Coronary Angiography). Developed in collaboration with the Society for Cardiac Angiography and Interventions. J Am Coll Cardiol 1999;33:1756-824. 
19. Bresee LC, Knudtson ML, Zhang J, et al. Likelihood of coronary angiography among First Nations patients with acute myocardial infarction. CMAJ 2014;186:E372-80.

20. Green AR, Carney DR, Pallin DJ, et al. Implicit bias among physicians and its prediction of thrombolysis decisions for black and white patients. J Gen Intern Med 2007;22:1231-8.

21. Bagchi AD, Stewart K, McLaughlin C, et al. Treatment and outcomes for congestive heart failure by race/ethnicity in TRICARE. Med Care 2011;49:489-95.

22. Sequist TD, Zaslavsky AM, Galloway JM, et al. Cardiac procedure use following acute myocardial infarction among American Indians. Am Heart J 2006;151:909-14.

23. LaVeist TA, Nuru-Jeter A, Jones KE. The association of doctorpatient race concordance with health services utilization. J Public Health Policy 2003;24:312-23.

24. Zestcott CA, Blair IV, Stone J. Examining the presence, consequences, and reduction of implicit bias in health care: a narrative review. Group Process Intergroup Relat 2016;19:528-42.

25. Kressin NR, Petersen LA. Racial differences in the use of invasive cardiovascular procedures: review of the literature and prescription for future research. Ann Intern Med 2001;135:352-66.

26. Statistics Canada. Aboriginal peoples: fact sheet for Manitoba. (Fact Sheet No. 89-656-x2016008). 2016 http://www.statcan.gc.ca/pub/ 89-656-x/89-656-x2016008-eng.pdf (accessed 6 Jul 2017).

27. Lavoie JG, Kaufert J, Browne AJ, et al. Negotiating barriers, navigating the maze: First Nation peoples' experience of medical relocation. Canadian Public Administration 2015;58:295-314.

28. Statistics Canada. Aboriginal peoples: fact sheet for Canada. (Fact Sheet No. 89-656-x2015001). 2015. Retrieved from http://www. statcan.gc.ca/pub/89-656-x/89-656-x2015001-eng.pdf (accessed 22 Jan 2018).

29. Lix L, Yogendran M, Burchill C, et al. Defining and validating chronic diseases: an administrative data approach. Winnipeg: Manitoba Centre for Health Policy, 2006.

30. Menec VH, Sirski M, Attawar D. Does continuity of care matter in a universally insured population? Health Serv Res 2005;40:389-400.

31. Menec VH, Shooshtari S, Nowicki S, et al. Does the relationship between neighborhood socioeconomic status and health outcomes persist into very old age? A population-based study. J Aging Health 2010;22:27-47.

32. Mustard CA, Derksen S, Berthelot JM, et al. Age-specific education and income gradients in morbidity and mortality in a Canadian province. Soc Sci Med 1997;45:383-97.

33. Quan H, Sundararajan V, Halfon P, et al. Coding algorithms for defining comorbidities in ICD-9-CM and ICD-10 administrative data. Med Care 2005;43:1130-9.

34. Martens PJ, Bartlett JG, Prior HJ, et al. What is the comparative health status and associated risk factors for the Métis? A populationbased study in Manitoba, Canada. BMC Public Health 2011;11:814.

35. Teng TH, Katzenellenbogen JM, Thompson SC, et al. Incidence of first heart failure hospitalisation and mortality in Aboriginal and non-Aboriginal patients in Western Australia, 2000-2009. Int J Cardiol 2014;173:110-7.

36. Jolly S, Kao C, Bindman AB, et al. Cardiac procedures among American Indians and Alaska Natives compared to non-Hispanic whites hospitalized with ischemic heart disease in California. J Gen Intern Med 2010;25:430-4.

37. Randall DA, Jorm LR, Lujic S, et al. Mortality after admission for acute myocardial infarction in Aboriginal and non-Aboriginal people in New South Wales, Australia: a multilevel data linkage study. BMC Public Health 2012;12:281.

38. Roe YL, Esterman A, McDermott R, et al. Management of indigenous patients presenting with non ST-segment elevation acute coronary syndrome in South Australia: a retrospective cohort study. Intern Med J 2016;46:202-13.

39. Quaas A, Curzen N, Garratt C. Non-clinical factors influencing the selection of patients with acute coronary syndromes for angiography. Postgrad Med J 2004;80:411-4.

40. Province of Manitoba. Annual Statistics 2010-2011. http://www.gov. $\mathrm{mb} . \mathrm{ca} / \mathrm{health} / \mathrm{annstats} / \mathrm{as} 1011$. pdf (accessed 27 Oct 2017).

41. Province of Manitoba. Diabetes in Manitoba 1989 to 2006. https:// www.gov.mb.ca/health/primarycare/providers/chronicdisease/ diabetes/docs/diabetes100.pdf (accessed 27 Oct 2017).

42. Chen J, Rathore SS, Radford MJ, et al. Racial differences in the use of cardiac catheterization after acute myocardial infarction. $N$ Engl $J$ Med 2001;344:1443-9.

43. Gulliford M, Figueroa-Munoz J, Morgan M, et al. What does 'access to health care' mean? J Health Serv Res Policy 2002;7:186-8.

44. Eisenberg JM. Sociologic influences on decision-making by clinicians. Ann Intern Med 1979;90:957-64.

45. Brown A. Acute coronary syndromes in indigenous Australians: opportunities for improving outcomes across the continuum of care. Heart Lung Circ 2010;19:325-36.

46. Browne AJ, Smye VL, Rodney P, et al. Access to primary care from the perspective of Aboriginal patients at an urban emergency department. Qual Health Res 2011;21:333-48.

47. Tang SY, Browne AJ. 'Race'matters: racialization and egalitarian discourses involving Aboriginal people in the Canadian health care context. Ethn Health 2008;13:109-27.

48. Schröder SL, Fink A, Hoffmann L, et al. Socioeconomic differences in the pathways to diagnosis of coronary heart disease: a qualitative study. Eur J Public Health 2017;27:1055-60.

49. Peiris D, Brown A, Cass A. Addressing inequities in access to quality health care for indigenous people. CMAJ 2008;179:985-6.

50. Browne AJ, Smye V. A post-colonial analysis of healthcare discourses addressing aboriginal women. Nurse Res 2002;9:28-41.

51. Frohlich KL, Ross N, Richmond C. Health disparities in Canada today: some evidence and a theoretical framework. Health Policy 2006;79:132-43.

52. McGibbon EA. Oppression: A social determinant of health. Canada: Fernwood Pub, 2012.

53. Katz A, Enns J, Kinew KA. Canada needs a holistic First Nations health strategy. CMAJ 2017;189:E1006-7.

54. King M, Smith A, Gracey M. Indigenous health part 2: the underlying causes of the health gap. Lancet 2009;374:76-85.

55. Bailey ZD, Krieger N, Agénor $M$, et al. Structural racism and health inequities in the USA: evidence and interventions. Lancet 2017;389:1453-63.

56. Atzema CL, Khan S, Lu H, et al. Cardiovascular disease rates, outcomes, and quality of care in Ontario Métis: a population-based cohort study. PLoS One 2015;10:e0121779.

57. Ferguson JA, Adams TA, Weinberger M, Busby HK, Roudebush $\mathrm{RL}$. Racial differences in cardiac catheterization use and appropriateness. Am J Med Sci 1998;315:302-6.

58. Adelson N. The embodiment of inequity: health disparities in aboriginal Canada. Can J Public Health 2005;96:S45-61. 